\title{
Factors Associated with Severe Late Toxicity After Concurrent Chemoradiation for Locally Advanced Head and Neck Cancer: An RTOG Analysis
}

\author{
Mitchell Machtay, MD \\ Thomas Jefferson University, mitchell.machtay@jefferson.edu \\ Jennifer Moughan, MS \\ RTOG Headquarters and Statistical Center and the American College of Radiology, Philadelphia \\ Andrew Trotti, MD \\ Moffitt Cancer Center of University of South Florida, Tampa \\ Adam S. Garden, MD \\ MD Anderson Cancer Center, Houston \\ follow this and additional wórks at: https://jdc.jefferson.edu/bodinejournal \\ ¿ndat Sf Heber MOgy Commons \\ MDAnderson cancer Genter Houston
}

\author{
Ree nextpagefor additional authors \\ Machtay, MD, Mitchell; Moughan, MS, Jennifer; Trotti, MD, Andrew; Garden, MD, Adam S.; Weber, MD, \\ Randal S.; Cooper, MD, Jay S.; Forastiere, MD, Arlene; and Ang, MD, K. Kian (2008) "Factors Associated \\ with Severe Late Toxicity After Concurrent Chemoradiation for Locally Advanced Head and Neck Cancer: \\ An RTOG Analysis," Bodine Journal: Vol. 1 : Iss. 1 , Article 7. \\ DOI: https://doi.org/10.29046/TBJ.001.1.006 \\ Available at: https://jdc.jefferson.edu/bodinejournal/vol1/iss1/7
}

This Article is brought to you for free and open access by the Jefferson Digital Commons. The Jefferson Digital Commons is a service of Thomas Jefferson University's Center for Teaching and Learning (CTL). The Commons is a showcase for Jefferson books and journals, peer-reviewed scholarly publications, unique historical collections from the University archives, and teaching tools. The Jefferson Digital Commons allows researchers and interested readers anywhere in the world to learn about and keep up to date with Jefferson scholarship. This article has been accepted for inclusion in Bodine Journal by an authorized administrator of the Jefferson Digital Commons. For more information, please contact: JeffersonDigitalCommons@jefferson.edu. 
Factors Associated with Severe Late Toxicity After Concurrent Chemoradiation for Locally Advanced Head and Neck Cancer: An RTOG Analysis

\section{Authors}

Mitchell Machtay, MD; Jennifer Moughan, MS; Andrew Trotti, MD; Adam S. Garden, MD; Randal S. Weber, MD; Jay S. Cooper, MD; Arlene Forastiere, MD; and K. Kian Ang, MD 


\section{Factors Associated with Severe Late Toxicity After Concurrent Chemoradiation for Locally Advanced Head and Neck Cancer: An RTOG Analysis}

Mitchell Machtay, MD', Jennifer Moughan, $\mathrm{MS}^{2}$, Andrew Trotti, MD³, Adam S. Garden, $\mathrm{MD}^{4}$, Randal S. Weber, $\mathrm{MD}^{5}$, Jay S. Cooper, $\mathrm{MD}^{6}$, Arlene Forastiere, $\mathrm{MD}^{7}$, K. Kian Ang, $\mathrm{MD}^{4}$

\begin{abstract}
1 Jefferson Medical College and Kimmel Cancer Center of Thomas Jefferson University, Philadelphia; ${ }^{2}$ RTOG Headquarters and Statistical Center and the American College of Radiology, Philadelphia; ${ }^{3}$ Moffitt Cancer Center of University of South Florida, Tampa; Departments of ${ }^{4}$ Radiation Oncology and ${ }^{5} \mathrm{Head}$ and Neck Surgery at MD Anderson Cancer Center, Houston; ${ }^{6}$ Maimonides Medical Center, New York; and 7 Johns Hopkins University Medical Center, Baltimore.
\end{abstract}

The following article is Reprinted with permission.(c) American Society of Clinical Oncology. All rights reserved. Machtay, M. et al: J. Clin. Oncol. 26 (21), 2008:3582-3589.

\section{Purpose}

Concurrent chemoradiotherapy (CCRT) for squamous cell carcinoma of the head and neck (SCCHN) increases both local tumor control and toxicity. This study evaluates clinical factors that are associated with and might predict severe late toxicity after CCRT.

\section{Methods}

Patients were analyzed from a subset of three previously reported RTOG trials of concurrent chemoradiotherapy for locally advanced SCCHN (RTOG 91-11; 97-03; and 99-14). Severe late toxicity was defined in this secondary analysis as chronic Grade 3-4 pharyngeal/laryngeal toxicity (RTOG/EORTC late toxicity scoring system) and/or requirement for a feeding tube $\geq 2$ years after registration and/or potential treatment-related death (e.g. pneumonia) within 3 years. Case-control analysis was performed, with a multivariable logistic regression model that included pre-treatment and treatment potential factors.

\section{Results}

A total of 230 patients were evaluable for this analysis, 99 cases (patients with severe late toxicities) and 131 controls; thus $43 \%$ of evaluable patients had a severe late toxicity. On multivariable analysis, significant variables correlated with the development of severe late toxicity were older age (odds ratio 1.05 per year; $\mathrm{p}=0.001$ ); advanced T-stage (odds ratio 3.07; $\mathrm{p}=0.0036$ ); larynx/hypopharynx primary site (odds ratio 4.17; $\mathrm{p}=0.0041$ ); and neck dissection after chemo-RT (odds ratio 2.39; $\mathrm{p}=0.018$ ).

\section{Conclusions}

Severe late toxicity following CCRT is common. Older age, advanced T-stage, and larynx/ hypopharynx primary site were strong independent risk factors. Neck dissection after CCRT was associated with an increased risk of these complications.

\section{Background/Introduction}

Concurrent chemoradiotherapy (CCRT) is a standard treatment for patients with locally advanced squamous cell carcinoma of the head and neck (SCCHN) treated non-surgically. Meta-analyses show an improved 5 -year survival by approximately $8 \%$ when CCRT is compared to radiotherapy alone $e^{1,2}$. The advantage of this approach with respect to disease free survival and local-regional control is greater than $8 \% \%^{3-6,7-10}$.

While there are undisputed advantages to CCRT for local-regional control, it increases toxicity when compared to radiotherapy alone ${ }^{11}$. Many studies have focused on acute toxicity, particularly mucositis, as summarized in a meta-analysis by Trotti et al. ${ }^{12}$. Comprehensive data on late toxicity from randomized trials of RT +/chemotherapy, however, are sparse. Latetoxicity may include long-term severe dysphagia and its related effects, including dependence upon a feeding tube, and have a profound effect on quality of life. The increased incidence of these serious, potentially permanent effects after CCRT is concerning, leading some to question as to whether chemoradiotherapy is truly a major improvement in the therapeutic ratio over radiotherapy alone. ${ }^{13}$

Starting approximately 15 years ago, the RTOG conducted a series of prospective clinical trials using CCRT for locally advanced SCCHN. General data on efficacy and early and subacute toxicity have been reported ${ }^{14-16}$. It is likely, however, that each individual study is underpowered for a thorough analysis of late effects, given sample size and patient attrition duetomortalityandothercauses. Consequently, we performed a secondary analysis of severelate toxicities from these several trials, specifically focusing on late toxicities and mortality related to pharyngolaryngeal dysfunction. An analysis of potential factors associated with severe late toxicities was undertaken.

\section{Materials/Methods}

As noted above, the three prospective trials analyzed for this paper have been previously reported. All three studies required an acceptable performance status $(60-100 \%$ by Karnofsky scale); non-metastatic stage III/IV SCCHN; and good hematologic, renal, hepatic and cardiovascular function.

Briefly, the three studies are:

RTOG 91-11 ${ }^{14}$ : A phase III trial of larynxpreserving radiotherapy or chemoradiotherapy for selected Stage III/IV larynx cancer. For this analysis, only the concurrent chemoradiotherapy arm was studied; this treatment in this arm consisted of 70 Gy in conventionally fractionated radiotherapy (XRT) - 2 Gy once daily - plus three cycles of high dose 
cisplatin (100 mg/m2, Weeks 1,4 , and 7). There were 172 patients in this arm from RTOG 91-11; 88 patients were evaluable for this analysis of late toxicity.

RTOG 97-03 ${ }^{17}$ : A Phase IIR trial of several novel regimens of concurrent chemoradiotherapy for stage III/IV head and neck cancer (excluding patients who were eligibile for RTOG 91-11). This study included three arms. Arms 1 and 3 utilized conventionally fractionated XRT as per 9111. Arm 1 chemotherapy was infusional 5-FU and cisplatin, both given daily during the last two weeks of XRT. Arm 3 chemotherapy was once weekly cisplatin $(20 \mathrm{mg} / \mathrm{m} 2 /$ week $)$ and paclitaxel $(30 \mathrm{mg} / \mathrm{m} 2 /$ week $)$. Arm 2 chemoradiotherapy was modeled upon the prospective phase II trials performed by the University of Chicago. In Arm 2, although the total XRT dose remained 70 Gy in 2 Gy fractions, it was delivered over 13 weeks (week-on, week-off technique); chemotherapy in Arm 2 consisted of concurrent infusional 5-FU and hydroxyurea. There were 231 patients in RTOG 97-03; 102 patients were evaluable for this analysis of late toxicity.

RTOG 99-14 ${ }^{16}$ : A Phase II trial of accelerated radiotherapy with concurrent chemotherapy for stage III/IV head and neck cancer. This single arm phase II study consisted of accelerated concomitant boost radiotherapy to 72 Gy over 6 weeks (as per the concomitant boost arm of RTOG 90-03), with two cycles of high dose cisplatin ( $100 \mathrm{mg} / \mathrm{m} 2$ weeks 1 and 4). There were 76 patients in RTOG 99-14; 40 patients were evaluable for this analysis of late toxicity.

All of these studies used conventional radiotherapy techniques, mostly 2-dimensional planning and delivery. No patient received intensity modulated radiation therapy (IMRT). For this report, a severe late toxicity was defined as any or all of the following events:

- Grade 3 or greater toxicity (RTOG/EORTC Late Toxicity Criteria) present $>180$ days after the start of XRT and clearly related to dysfunction of the larynx and/or pharynx (e.g. dysphagia)

- Requirement for a feeding tube/gastrostomy 2 years or longer after the start of XRT.

- Death without cancer progression and from an uncertain cause in which laryngeal dysfunction is suspected to be a contributing factor (e.g. pneumonia) $\leq 3$ years from the date of randomization. Patients who died of unknown causes were included in this category. Review of these deaths was performed by one of the study authors (MM) in a manner blinded to any of the patient's clinical pre-treatment and/or treatment related characteristics.

Patients who suffered one or more qualifying severe late toxicity events were only considered to be one "case."

Patients with severe laryngopharynx dysfunction due to cancer, prior to the start of treatment, were excluded because of the potential confounding nature of tumor destruction of critical normal tissues (See Table 1). In RTOG 91-11, the determination of severe pre-treatment laryngopharynx dysfunction was based on patients' on-study data collection form, which scored airway obstruction and dysphagia on a 4-point scale (none, mild, moderate, severe/life-threatening); patients with severe/life-threatening airway obstruction and/or dysphagia based on this form were excluded. In RTOG 91-11, data on pre-treatment use of feeding tubes were not collected. In RTOG 97-03 and RTOG 99-14, pre-treatment feeding tube data were collected, and this was used as the primary means of defining patients with pre-treatment severe laryngopharynx dysfunction.

Patients with missing/inevaluable data or early death from acute toxicity were also excluded.

\section{Statistical Analysis}

Frequency tables with counts and percentages were used to describe pretreatment and treatment characteristics for each group. Univariate and multivariable logistic regression models were used to identify associations of pretreatment and treatment-related factors with severe late toxicity. All models were stratified by the 5 treatment arms described above. The following factors were studied: age (continuous variable); gender; race (non-black vs. black); KPS (60-80 vs. 90-100); hemoglobin (continuous variable); weight loss pre-treatment (continuous variable); T-stage (T1/2 vs. T3/4); N Stage (Nx/0/1 vs. N2 vs. N3); Tumor site (oral cavity/oropharynx vs. larynx/hypopharynx); radiotherapy dose received as assessed by late effects BED model (total RT dose multiplied by $(1+[$ dose/fraction size $] \div 3)$ : continuous variable); chemotherapy dose received ( $<85 \%$ of planned dose vs. $>85 \%$ of planned dose); and post-RT neck dissection (yes vs. no). Variables' levels were grouped in order to avoid small cell counts. A stepwise selection procedure was used to build the multivariable logistic regression model using the above pretreatment/treatment variables. Entry criterion was set at $\mathrm{p}<0.05$. The odds ratios (OR) for each variable in the final model along with their $95 \%$ confidence intervals and $\mathrm{p}$-values are reported. The odds ratios estimate how much more (less) likely it is to be in the case group versus the control group among patients with the specific variable level's characteristic compared to those patients in the reference level (RL), after stratifying for treatment arm. The cumulative incidence method was used to estimate time to severe late toxicity and levels for pre-treatment/ treatment-related variables were compared using the Gray's test ${ }^{18,19}$.

Table 1. Summary of Patients Excluded from this Analysis

\begin{tabular}{|c|c|c|c|c|}
\hline & $\begin{array}{l}\text { RTOG 91-11 } \\
\text { (Original } \\
\mathrm{N}=172)\end{array}$ & $\begin{array}{l}\text { RTOG 97-03 } \\
(\text { Original } \\
\mathrm{N}=231)\end{array}$ & $\begin{array}{l}\text { RTOG 99-14 } \\
\text { (Original } \\
\mathrm{N}=76)\end{array}$ & $\begin{array}{l}\text { Total } \\
\text { (Original } \\
\mathrm{N}=479 \text { ) }\end{array}$ \\
\hline \multicolumn{5}{|l|}{ Reason for Exclusion } \\
\hline $\begin{array}{l}\text { Severe Pre-treatment } \\
\text { Airway Obstruction }\end{array}$ & 15 & - & - & 15 \\
\hline $\begin{array}{l}\text { Severe Pre-treatment } \\
\text { Dysphagia }\end{array}$ & 5 & - & - & 5 \\
\hline $\begin{array}{l}\text { Pre-treatment Feeding } \\
\text { Tube Dependence }\end{array}$ & - & 62 & 18 & 80 \\
\hline $\begin{array}{l}\text { Total Excluded due to } \\
\text { Severe pre-treatment } \\
\text { laryngopharynx } \\
\text { dysfunction }\end{array}$ & 20 & 62 & 18 & 100 \\
\hline $\begin{array}{l}\text { Death from Acute } \\
\text { toxicity }\end{array}$ & 2 & 3 & 1 & 6 \\
\hline $\begin{array}{l}\text { Tumor Recurrence/ } \\
\text { death }<3 \text { yrs followup. }\end{array}$ & 52 & 62 & 16 & 130 \\
\hline Missing Data & 10 & 2 & 1 & 13 \\
\hline Grand Total Excluded & 84 & 129 & 36 & 249 \\
\hline $\begin{array}{l}\text { Total Analyzable } \\
\text { for this study }\end{array}$ & 88 & 102 & 40 & 230 \\
\hline $\begin{array}{l}\text { Abbreviations as in Table } 4 . \\
\text { Reference level: } \mathrm{GTV} \leq 45 \mathrm{~cm}^{3} \text {, } \\
{ }^{*} \text { Chi-square test using Cox pro }\end{array}$ & $\begin{array}{l}\text { dose } 90.3 \text { Gy. } \\
\text { oportional hazards } \mathrm{m}\end{array}$ & & & \\
\hline
\end{tabular}


Table 2. Summary of patients with severe late toxicities (cases) and patients without severe late toxicities (controls)

\begin{tabular}{|c|c|c|}
\hline & $\begin{array}{c}\text { Case Group } \\
(\mathbf{n}=99)\end{array}$ & $\begin{array}{c}\text { Control Group } \\
(\mathrm{n}=131)\end{array}$ \\
\hline \multicolumn{3}{|l|}{$\overline{\text { Age }}$} \\
\hline Median & 60 & 56 \\
\hline Range & $33-78$ & $26-78$ \\
\hline Age $\leq 70$ & $85(86 \%)$ & $118(90 \%)$ \\
\hline Age $>70$ & $14(14 \%)$ & $13(10 \%)$ \\
\hline \multicolumn{3}{|l|}{ Gender } \\
\hline Male & $78(79 \%)$ & $99(76 \%)$ \\
\hline Female & $21(21 \%)$ & $32(24 \%)$ \\
\hline \multicolumn{3}{|l|}{ Race } \\
\hline Non-Black & $90(91 \%)$ & $120(92 \%)$ \\
\hline Black & $9(9 \%)$ & $11(8 \%)$ \\
\hline \multicolumn{3}{|l|}{ KPS } \\
\hline 60-80 & $24(24 \%)$ & $20(15 \%)$ \\
\hline $90-100$ & $75(76 \%)$ & $111(85 \%)$ \\
\hline \multicolumn{3}{|l|}{ Hemoglobin } \\
\hline Median & 14.3 & 14.2 \\
\hline Range & $7.1-18.2$ & $9.9-18.2$ \\
\hline $\mathrm{Hgb} \leq 13.5 \mathrm{gm} / \mathrm{dl}$ & $28(28 \%)$ & $43(33 \%)$ \\
\hline $\mathrm{Hgb}>13.5 \mathrm{gm} / \mathrm{dl}$ & $71(72 \%)$ & $88(67 \%)$ \\
\hline \multicolumn{3}{|c|}{ Weight Loss in Previous 6 months $(\mathrm{kg})$} \\
\hline Mean & 3.9 & 2.8 \\
\hline$\leq 5 \mathrm{~kg}$ & $78(79 \%)$ & $112(86 \%)$ \\
\hline$>5 \mathrm{~kg}$ & $21(21 \%)$ & $19(14 \%)$ \\
\hline \multicolumn{3}{|l|}{ T Stage } \\
\hline $\mathrm{T} 1 / \mathrm{T} 2$ & $18(18 \%)$ & $39(30 \%)$ \\
\hline $\mathrm{T} 3 / \mathrm{T} 4$ & $81(82 \%)$ & $92(70 \%)$ \\
\hline \multicolumn{3}{|l|}{ N Stage } \\
\hline $\mathrm{NX} / \mathrm{N} 0 / \mathrm{N} 1$ & $47(47 \%)$ & $63(48 \%)$ \\
\hline N2 & $42(42 \%)$ & $58(44 \%)$ \\
\hline N3 & $10(10 \%)$ & $10(8 \%)$ \\
\hline \multicolumn{3}{|l|}{ Tumor Site } \\
\hline Oral cavity/oropharynx & $42(42 \%)$ & $71(54 \%)$ \\
\hline Oral Cavity & $7(7 \%)$ & $5(4 \%)$ \\
\hline Oropharynx & $35(35 \%)$ & $66(50 \%)$ \\
\hline Larynx/hypopharynx & $57(58 \%)$ & $60(46 \%)$ \\
\hline Larynx & $41(41 \%)$ & $51(39 \%)$ \\
\hline Hypopharynx & $16(16 \%)$ & $9 \quad(7 \%)$ \\
\hline \multicolumn{3}{|l|}{$\begin{array}{l}\text { Radiotherapy Dose-Intensity } \\
\text { delivered (BED) }\end{array}$} \\
\hline Mean & $115 \mathrm{~Gy}$ & $116 \mathrm{~Gy}$ \\
\hline Median & $117 \mathrm{~Gy}$ & $117 \mathrm{~Gy}$ \\
\hline Range & $67-117 \mathrm{~Gy}$ & $111-126 \mathrm{~Gy}$ \\
\hline \multicolumn{3}{|l|}{ Neck Dissection after RT } \\
\hline Yes & $26(26 \%)^{*}$ & $21(16 \%)$ \\
\hline No & $73(74 \%)$ & $110(84 \%)$ \\
\hline \multicolumn{3}{|l|}{$\begin{array}{l}\text { Chemotherapy dose-intensity } \\
\text { delivered }\end{array}$} \\
\hline$<85 \%$ & $22(22 \%)$ & $29(22 \%)$ \\
\hline$\geq 85 \%$ & $77(78 \%)$ & $102(78 \%)$ \\
\hline
\end{tabular}

\section{Results}

The original, potential patient population from these three studies was 479. However, there were 130 patients excluded because of local-regional failure or death due to cancer, 100 patients excluded because of severe pre-treatment laryngopharynx dysfunction due to tumor, 13 patients excluded because of missing data, and 6 patients excluded because of early death due to acute toxicity (see Table 1);. Thus, the overall evaluable sample size for this report was 230 patients. The median followup for the patient population is 2.96 years.

Of these 230 patients, 99 patients (cases) had severe late toxicity and 131 patients (controls) did not have severe late toxicity. This results in a crude rate of late toxicity of $43 \%$. It should be noted that if the entire population of patients $(\mathrm{N}=479)$ from all three studies are analyzed (as is often performed for studies of late effects) the crude rate would appear to be $21 \%$., considerably lower than the data reported here. An actuarial plot of "Time to Severe Late Toxicity" for all 230 evaluable patients is shown in Figure 1.

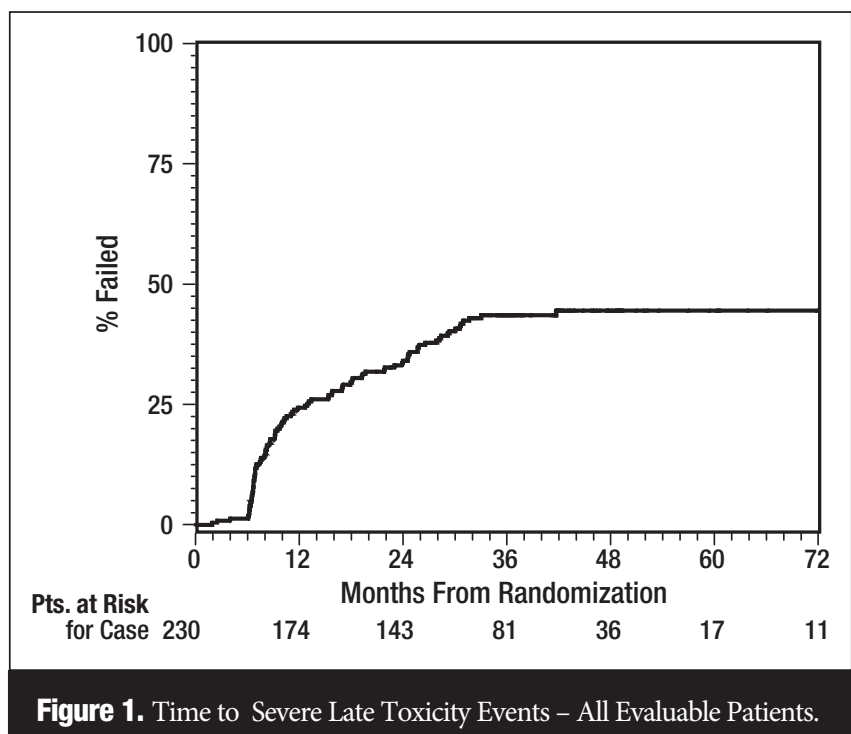

Table 3. Types of late toxicity events seen by trial

\begin{tabular}{|c|c|c|c|c|}
\hline & 91-11 & 97-03 & $99-14$ & Total \\
\hline $\begin{array}{l}\text { Feeding Tube Dependence } \\
>2 \text { yrs. Post RT }\end{array}$ & $-^{*}$ & \multicolumn{2}{|c|}{$29^{*}$} & 29 \\
\hline $\begin{array}{l}\text { Grade 3+ Pharyngeal } \\
\text { Dysfunction (RTOG late } \\
\text { toxicity criteria) }\end{array}$ & 16 & 28 & 19 & 63 \\
\hline $\begin{array}{l}\text { Grade 3+ Laryngeal } \\
\text { Dysfunction (RTOG late } \\
\text { toxicity criteria) }\end{array}$ & 22 & 6 & 0 & 28 \\
\hline Death & 11 & 9 & 2 & 22 \\
\hline Other (e.g. infection, fistula) & 3 & 0 & 1 & 4 \\
\hline Any & $38^{* *}$ & $40^{\star *}$ & $21^{* *}$ & $99^{* *}$ \\
\hline $\begin{array}{l}\text { No Severe late toxicity } \\
\text { event (controls) }\end{array}$ & 50 & 62 & 19 & 13 \\
\hline $\begin{array}{l}{ }^{*} \text { Feeding tube data were not collected } \\
{ }^{*} \text { Numbers do not always add up alon } \\
\text { toxicity event. }\end{array}$ & $\begin{array}{l}\text { RTOG 91-11. } \\
\text { s, due to son }\end{array}$ & atients hav & more than & \\
\hline
\end{tabular}


Figure 2. Time to Severe Late Toxicity Subgoup Analyses based on Patient/Treatment Characteristics

(All graphs exclude 2 patients who had neck dissection after already experiencing a severe late toxicity.)
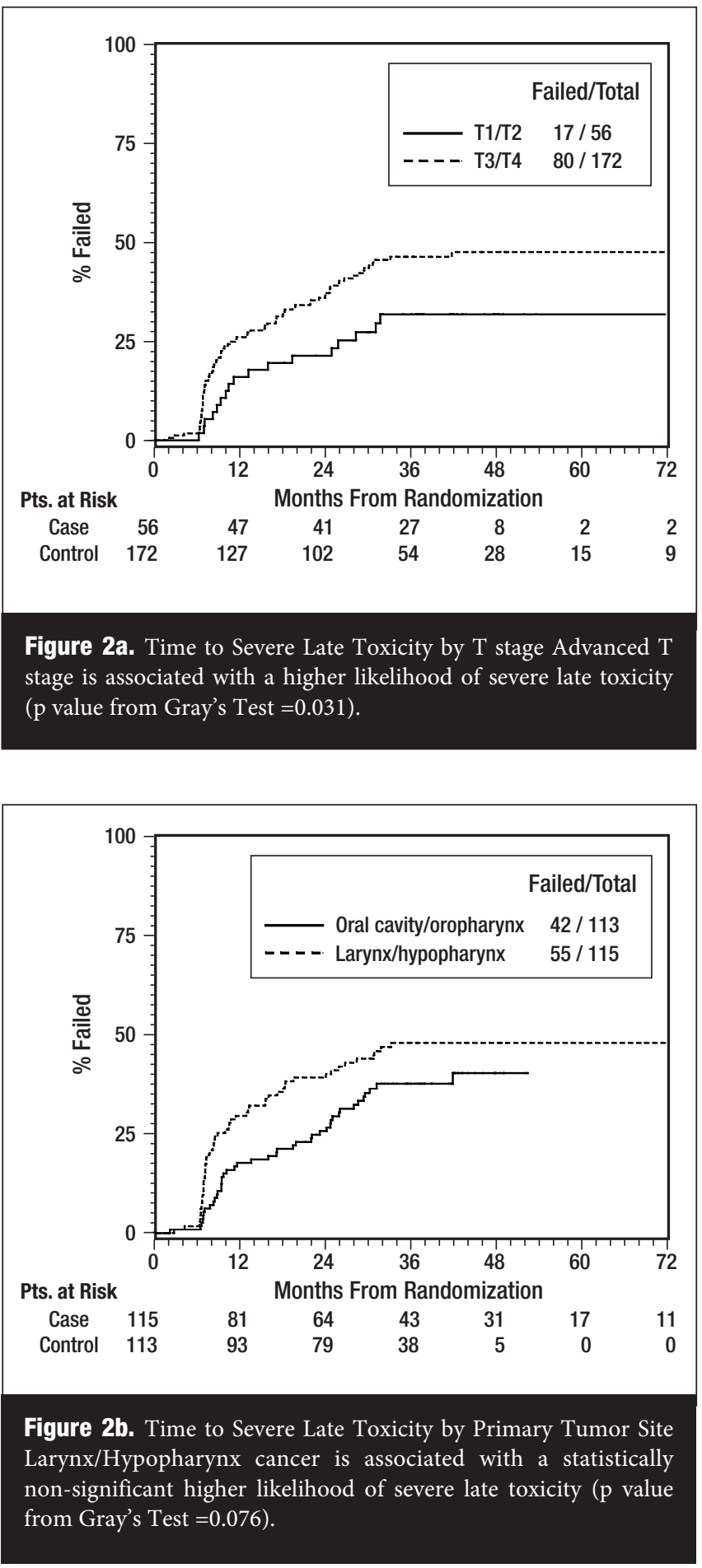

The pre-treatment characteristics of these 230 patients are shown in Table 2 , including both pre-treatment and treatment-related characteristics. Table 3 shows an accounting of the types of late toxicity events observed in this analysis; most were related to swallowing function (particularly in RTOG 97-03 and RTOG 99-14) or laryngeal dysfunction (RTOG 91-11).

Patients with severe toxicities (cases) were more likely to be older and/or to have larger T-stage and/or larynx/hypopharynx primary cancer. On univariate analysis, there were no statistically significant differences in the rates of late effects based on each individual study/arm.

Univariate logistic regression analysis of pre-treatment and treatmentrelated variables is shown in Table 4. Actuarial estimates of time to severe late toxicity as a function of T-stage, primary tumor site, and neck dissection are shown in Figures $2 \mathrm{a}$ to $2 \mathrm{c}$, respectively. The most significant pre-treatment factor associated with severe late toxicity was age, analyzed as a continuous variable $(\mathrm{p}=0.0038)$ - older patients were significantly more likely to have severe late toxicity. T-stage (T3-4 more likely to have severe late toxicity) and tumor site (larynx/hypopharynx more likely to have severe late toxicity) were also statistically significant factors. On univariate analysis, none of the treatment-related variables were statistically significant except BED $(\mathrm{p}<0.0001)$, with a paradoxical negative association between BED and severe late toxicity. The $\mathrm{p}$-value for potential association between severe late toxicity and neck dissection after RT was 0.145 .

The results of a multivariable logistic regression model analysis are shown in Table 4. Age, T-stage and tumor site remained statistically significant. In addition, a positive association between post-treatment neck dissection and severe late toxicity was noted $(\mathrm{p}=0.02)$. Specifically, out of the 230 patients in this study, 47 (20\%) underwent post-treatment neck dissection; this included $22 \%$ of the oral cavity/oropharynx patients and $19 \%$ of the larynx/hypopharynx patients. These 47 patients had a

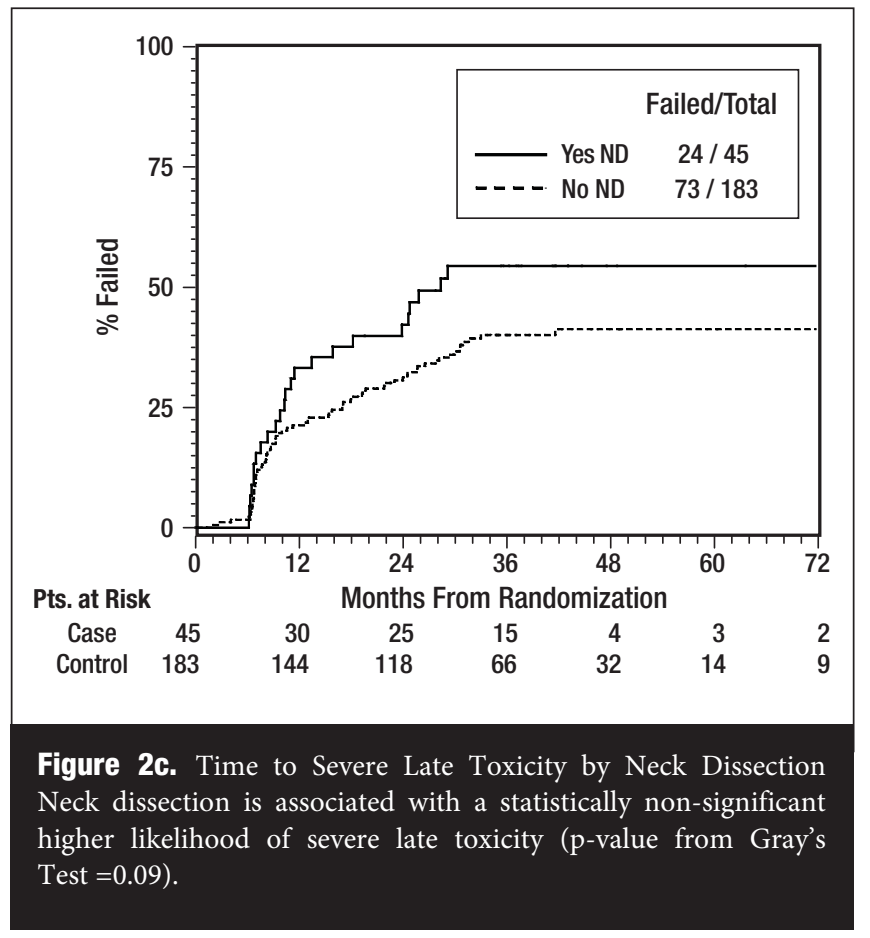


Table 4. Univariate and Multivariable Logistic Regression Models to Identify Covariates that are associated with severe late toxicity.

\begin{tabular}{lccccc}
\hline & $\begin{array}{c}\text { Univariate } \\
\text { Analysis }\end{array}$ & \multicolumn{3}{c}{$\begin{array}{c}\text { Multivariate } \\
\text { Analysis }\end{array}$} \\
\hline Covariates & $\begin{array}{c}\text { Odds } \\
\text { Ratio }\end{array}$ & p-value & $\begin{array}{c}\text { Odds } \\
\text { Ratio }\end{array}$ & $\begin{array}{c}\mathbf{9 5 \%} \\
\text { confidence } \\
\text { Interval }\end{array}$ & p value \\
\hline $\begin{array}{l}\text { Age } \\
\text { Continuous variable }\end{array}$ & $1.043^{*}$ & 0.0038 & $1.05^{*}$ & {$[1.02,1.09]$} & 0.001 \\
\hline $\begin{array}{l}\text { Gender } \\
\text { Female } \\
\text { Male }\end{array}$ & RL & & & & \\
\hline
\end{tabular}

\section{Race}

Non-Black

Black

RL

$1.165 \quad 0.7458$

\section{KPS}

$\begin{array}{lll}60-80 & 1.892 & 0.0612 \\ 90-100 & \end{array}$

90-100

\section{Hemoglobin (gm\%)}

Continuous Variable $\quad 1.005 \quad 0.9528$

\begin{tabular}{lccccc}
\hline $\begin{array}{l}\text { Weight loss (kg) } \\
\text { Continuous Variable }\end{array}$ & 1.018 & 0.3733 & & & \\
\hline $\begin{array}{l}\text { T Stage } \\
\text { T1/T2 }\end{array}$ & RL & & RL & & \\
T3/T4 & 2.041 & 0.0349 & 3.07 & {$[1.444,6.54]$} & 0.0036 \\
\hline N Stage & & & & & \\
NX/N0/N1 & RL & & & \\
N2 & 0.942 & 0.8464 & & \\
N3 & 1.297 & 0.6108 & & \\
\hline
\end{tabular}

\section{Tumor Site}

Oral cavity/oropharynx RL

RL

$\left.\begin{array}{llllll}\text { Larynx/hypopharynx } & 2.955 & 0.0131 & 4.17 & {[1.57,11.03}\end{array}\right] \quad 0.0041$

BED (Toxicities)

based on Actual

Dose/Fx (Gy)

Continuous Variable

Neck dissection after $\mathrm{RT}^{* *}$

$\begin{array}{lccccc}\text { Yes } & 1.632 & 0.145 & 2.39 & {[1.16,4.92]} & 0.018 \\ \text { No } & \text { RL } & & \text { RL } & & \end{array}$

Percent of chemotherapy

received relative to the

protocol amount

$\begin{array}{lcc}<85 \% & 1.033 & 0.9216 \\ \geq 85 \% & \text { RL }\end{array}$

Abbreviations: $\mathrm{RL}=$ reference level; $\mathrm{RT}=$ radiation therapy

* The odds ratio of 1.043 for age indicates that for each one year increase in age, patients have 1.043 times higher odds of being in the case group (having a severe late toxicity) than being in the control group (not having a severe late toxicity).

** This excludes 2 patients who had neck dissection after having already experiencing a severe late toxicity. crude rate of severe late toxicity of 55\% (compared with $40 \%$ for the 183 patients who did not undergo neck dissection).

Of note, besides neck dissection, other treatment-related factors were not associated with severe late effects. Although the most aggressive radiotherapy fractionation trial (RTOG 99-14, which used concomitant boost XRT + cisplatin) numerically had the highest crude rate of severe late toxicity $(21 / 40=53 \%)$, there were no statistically significant differences among the trial arms.

As noted in Table 4, radiotherapy dose delivered (as analyzed as biologically equivalent dose [BED]) was significant on univariate analysis (with a paradoxical relationship in which lower RT dose was associated with higher risk) but fell out of the multivariable model. The amount of chemotherapy delivered was not statistically significant in either model.

\section{Discussion}

This retrospective analysis of several prospective trials shows that the rate of severe late toxicity after CCRT for SCCHN is high, particularly with the analysis methodology used here. Specifically, in this study, patients with severe pre-treatment laryngopharynx dysfunction and patients with early tumor recurrence were excluded a priori from this analysis. Thus, the number of patients "at risk" for a severe late toxicity event is much smaller than the original treated population. This technique closely approximates the use of actuarial analysis of late complications, a technique which yields a higher rate of complications than simply reporting crude rate of complications, as reported by Bentzen et al. ${ }^{20}$ A true actuarial analysis of late complications in head and neck cancer is difficult, because it is not easy to ascertain a date of onset of a late complication in any one individual patient (Figures 2a-2c). Our sample size of 230 patients makes this one of the largest studies of late toxicity in the concurrent chemoradiotherapy era.

In this study, several factors that correlated with severe late toxicity were identified. Since this is a retrospective study, the data must be considered hypothesis-generating rather than definitive. Some caveats result from the fact that these studies were conducted over a 10-year time period (approximately 1991-2001), with variations in eligibility, treatment, and data collection techniques. A second problem inherent to retrospective studies like ours is that a number of potentially important factors may not have been collected at all. For example our database does not include information on tumor volume, cardiopulmonary co-morbidity, and amount of tobacco consumed in followup.

However, it is logical to believe that age, tumor site and tumor stage would predict for greater likelihood of severe late toxicity. The finding that post-treatment neck dissection was significantly associated with severe late toxicity was somewhat more surprising, although this has been reported previously. The number of patients undergoing posttreatment neck dissection was relatively small (20\%, despite over $50 \%$ of the patients having N2-3 disease), and thus these data can not be considered conclusive. It is possible that selection bias could lead to this association; for example, patients with larger volume neck disease may be more likely to undergo neck dissection and may be more likely to have neck-tumor-related damage to adjacent normal tissues unrelated to the neck dissection. It is possible, though, that disturbance of the soft tissues of the neck via post-treatment neck dissection could cause added swallowing dysfunction, for example by increasing fibrosis in the neck and thus limiting the mobility of the laryngopharynx. It should be noted that a similar report of an association between severe late toxicity and post-treatment neck dissection was recently reported by researchers at 
Fox Chase Cancer Center ${ }^{21}$. If these findings are validated in additional, larger datasets, there may be important implications with respect to the controversy regarding neck dissection following chemoradiotherapy for patients with advanced neck disease.

The lack of significant association between cumulative radiotherapy dose delivery (or chemotherapy dose delivery) and severe late toxicity may be due to the narrow dose range prescribed and the generally excellent compliance. We are currently analyzing the detailed radiotherapy records (simulation films, dosimetry and treatment records) available at RTOG headquarters in order to estimate the doses received by individual normal tissue sub-structures within the head and neck. Several recent single-institution studies have rigorously analyzed the relationships between radiotherapy dose-volume-histograms for normal structures and the risk and severity of toxicities ${ }^{22,23}$.

Considering the widespread acceptance of CCRT for SCCHN over the last 10 years, there are relatively few detailed studies of late toxicities. GORTEC reported long-term followup from their randomized trial of radiotherapyaloneversus 5-FU/carboplatin/radiotherapy for oropharynx cancer; they did not find a significant difference in severe late toxicity ${ }^{24}$. However, there were fewer than 50 long-term survivors in that study. Staar reported that $51 \%$ of long-term survivors ( $>2$ years) after a very intense combination of accelerated fractionation radiotherapy and chemotherapy were dependent on feeding tubes ${ }^{8}$. With longer followup, that alarmingly high rate did decrease, and was not significantly worse than accelerated radiotherapy alone but the number of evaluable patients was relatively small ${ }^{25}$. Shiley reported that 4 of 13 (31\%) cancer-free survivors ( $>1$ year) after chemoradiotherapy required tube feedings for some or all of their nutrition ${ }^{26}$.

These data suggest that the CCRT has reached the limits of acceptable long-term toxicity. Dose intensity can not be easily increased without some new and effective technique(s) of protection against late effects. In the future, these may include modern techniques in radiotherapy technology ${ }^{27,28}$, or biopharmacologic radioprotectors ${ }^{29-31}$. Presently, however, these techniques have only succeeded in reducing xerostomia, not severe late dysphagia. Emphasis should therefore be on careful patient selection for aggressive treatment and swallowing exercises before during and after radiotherapy ${ }^{32,33}$. Some patients may benefit from more invasive procedures, such as dilatation of hypopharyngeal/esophageal stricture under anesthesia.

For some patient subpopulations the risks of concurrent chemoradiotherapy may outweigh the benefits. For example, subgroup analysis of a meta-analysis suggested that there was no significant survival benefit to CCRT in patients older than age $70^{1}$. Our data may add to the controversy regarding management of the elderly patient with head and neck cancer - if there is no significant survival benefit and a significant increase in late toxicity with concurrent chemoradiotherapy, should it be the standard of care in this patient population?

Our study has several limitations that should be discussed. First, it is a "meta-analysis" of three separate clinical trials, each of which had somewhat different eligibility criteria, chemoradiotherapy regimen, and year of activation. However, all of the patients did receive treatment that would be considered appropriate standard of care in today's oncology clinic. Second, our exclusion of patients with pre-existing severe laryngopharynx dysfunction from this analysis can be considered controversial. Although patients were excluded a priori, determining pre-existing severe laryngopharynx dysfunction is subjective. However, it should be noted that the determination of post-treatment severe laryngopharynx dysfunction (toxicity) is also subjective. It is extremely difficult to determine if severe dysfunction after treatment is the result of treatment or the result of the pre-existing cancer. By excluding patients with pre-treatment severe laryngopharynx dysfunction, we attempted to isolate the influence of treatment on outcomes. Third, our study is an exploratory analysis; while it is one of the larger series on late toxicity after chemoradiotherapy, the number of patients and number of events are relatively small. We plan to address this in the future with an analysis of the recently completed trial, RTOG 0129. This was a randomized trial of standard fractionation versus accelerated fractionation radiotherapy (with cisplatin in both arms). Preliminary acute and subacute toxicity data showed no significant differences between the two $\operatorname{arms}^{34}$. It is premature at this time to perform a detailed analysis of efficacy or late toxicity from that study. It is possible that with improved knowledge and experience with CCRT and supportive care available in the $21^{\text {st }}$ century, outcomes may be improved in RTOG 0129 compared to historical controls.

Ultimately, it should be remembered that for most patients with head and neck cancer, the highest priority is cure and length of survival ${ }^{35}$. Excessive concern about treatment toxicity should not prevent the use of proven aggressive multimodality treatment, provided the patient is well informed about the potential late sequelae of these aggressive treatment regimens.

\section{References}

1. Bourhis J, LeMaitre A, Baujat B, et al. Individual patients' data meta-analyses in head and neck cancer. Curr Opin Oncol 2007;19(3):188-94.

2. Pignon JP, Bourhis J, Domenge C, Designe L. Chemotherapy added to locoregional treatment for head and neck squamous cell carcinoma: three meta-analyses of updated individual data. Lancet 2000;355:949-55.

3. Brizel DM, Albers MA, Fisher SR, et al. Hyperfractionated irradiation with or without concurrent chemotherapy for locally advanced head and neck cancer. N Engl J Med 1998;328:1798-804.

4. Wendt TG, Grabenbauer CG, Rodel CM, et al. Simultaneous radiochemotherapy versus radiotherapy alone in advanced head and neck cancer: a randomized multicenter study. J Clin Oncol 1998;16:1318-24.

5. Calais G, Alfonsi M, Bardet E, et al. Randomized study comparing radiation alone RT versus concomitant chemotherapy and radiation therapy for advanced-stage oropharynx carcinoma. J Natl Cancer Inst 1999;91:2081-6.

6. Adelstein DA, Lavertu P, Saxton JP, et al. Mature results of a phase III trial comparing concurrent chemoradiotherapy with radiation therapy alone in patients with stage III and IV squamous cell carcinoma of the head and neck. Cancer 2000;88:876-83.

7. Olmi P, Crispino S, Fallai C, et al. Locoregionally advanced carcinoma of the oropharynx: conven tional radiotherapy vs. accelerated hyperfractionated radiotherapy vs. concomitant radiotherapy and chemotherapy - a multicenter randomized trial. Int J Radiat Oncol Biol 2003;55:78-92.

8. Staar S, Rudat V, Stuetzer $\mathrm{H}$, et al. Intensified hyperfractionated accelerated radiotherapy limits the additional benefit of simultaneous chemotherapy -- results of a multicentric randomized German trial in advanced head and neck cancer. Int J Radiat Oncol Biol Phys 2001;50:1161-71.

9. Budach V, Stuschke M, Budach W., et al. Hyperfractionated accelerated chemoradiation with concurrent fluorouracil-mitomycin is more effective than dose-escalated hyperfractionated accelerated radiation therapy alone in locally advanced head and neck cancer: final results of the radiotherapy cooperative clinical trials group of the German Cancer Society 95-06 prospective randomized trial. J Clin Oncol 2005;23(6):1125-35.

10. Bensadoun RJ, Benezery K, Dassonville O, , et al. French multicenter phase III randomized study testing concurrent twice-a-day radiotherapy and cisplatin/5-fluorouracil chemotherapy (BiRCF) in unresectable pharyngeal carcinoma: Results at 2 years (FNCLCC-GORTEC). Int J Radiat Oncol Biol Phys 2006;64(4):983-94.

11. Henk JM. Controlled trials of synchronous chemotherapy with radiotherapy in head and neck cancer: overview of radiation morbidity. Clin Oncol (Royal Coll Radiol) 1997;9:308-12.

12. Trotti A, Bellm LA, Epstein JB, et al. Mucositis incidence, severity and associated outcomes in patients with head and neck cancer receiving radiotherapy with or without chemotherapy: a systematic literature review. Radiother Oncol 2003;66:253-62

13. Stuben G, Thews O, Pottgen C, et al. Recombinant human erythropoietin increases the radiosensitivity of xenografted human tumours in anaemic nude mice. J Cancer Res Clin Oncol 2001;127:346-50. 
14. Forastiere AA, Goepfert H, Maor M, et al. Concurrent chemotherapy and radiotherapy for organ preservation in advanced laryngeal cancer. N Engl J Med 2003;349:2091-8.

15. Garden AS, Harris J, Vokes EE, et al. Preliminary results of Radiation Therapy Oncology Group 97-03: a randomized phase II trial of concurrent radiation and chemotherapy for advanced squamous cell carcinomas of the head and neck. J Clin Oncol 2004;22:2856-64.

16. Ang KK, Harris J, Garden A, et al. Concomitant boost radiation plus concurrent cisplatin for advanced head and neck carcinomas: Radiation Therapy Oncology Group phase II trial 99-14. J Clin Oncol 2005;23(13):3008-15.

17. Garden AS, Pajak, T., Vokes, E., Forastiere, A., Ridge, J., Jones, C., Horwitz, E., Glisson, B., Nabell L., Cooper, J., Demas, W., Gore, E. Preliminary results of RTOG 9703 - A Phase II Randomized Trial of Concurrent Radiation (RT) and Chemotherapy for Advanced Squamous Cell Carcinoma (SCC) of the Head and Neck (abstr.). In: Proc Am Soc Clin Oncol (ASCO); 2001; San Francisco 2001.

18. Kalbfleisch JD, Prentice RL. The Statistical Analysis of Failure Time Data. New York: John Wiley \& Sons; 1980:167-169.

19. Gray RJ. A class of K-sample tests for comparing the cumulative incidence of a competing risk Ann Statist. 1988; 16: 1141-1154.

20. Bentzen SM, Vaeth M, Pedersen DE, Overgaard J. Why actuarial estimates should be used in reporting late normal tissue effects of cancer treatment ... now! Int J Radiat Oncol Biol Phys 1995;32(5):1531-4.

21. Lango M, Ende K, Ahmad S, Feigenberg SJ, Ridge JA. Neck dissection following organ preservation protocols prolongs feeding tube dependence in patients with advanced head and neck cancer (abstr. \#5525). In: 2006 ASCO annual meeting; 2006; Atlanta: J Clin Oncol; 2006.

22. Dornfeld K, Simmons JR, Karnell L, et al. Radiation doses to structures within and adjacent to the larynx are correlated with long-term diet- and speech-related quality of life. Int J Radiat Oncol Biol Phys 2007;68(3):750-7.

23. Eisbruch A, Schwartz M, Rasch C, et al. Dysphagia and aspiration after chemoradiotherapy for head and neck cancer: which anatomic structures are affected and can they be spared by IMRT? Int J Radiat Oncol Biol Phys 2004;60:1425-39.

24. Denis F, Garaud P, Bardet E, et al. Final results of the 94-01 French head and neck oncology and radiotherapy group randomized trial coparing radiotherapy alone with concomitant radiochemotherapy in advanced-stage oropharynx carcinoma. J Clin Oncol 2004;22(1):69-76.

25. Semaru R, Mueller RP, Stuetzer H, Staar S, et al. Efficacy of intensified hyperfractionated and accelerated radiotherapy and concurrent chemotherapy with carboplatin and 5-0fluorouracil: updated results of a randomized multicentric trial in advanced head and neck cancer. Int $J$ Radiat Oncol Biol Phys 2006;64(5):1308-16.

26. Shiley SG, Hargunani C, Skoner JM, et al. Swallowing function after chemoradiation for advanced stage oropharyngeal cancer. Otolaryngol Head Neck Surg 2006;134(3):455-9.

27. Bucci MK, Bevan A, Roach Mr. Advances in radiation therapy: conventional to 3D, to IMRT, to 4D, and beyond. CA Cancer J Clin 2005;55(2):117-34.

28. Feng FY, Kim HM, Lyden TH, et al. Intensity-modulated radiotherapy of head and neck cancer aiming to reduce dysphagia: early dose-effect relationships for the swallowing structures. Int $J$ Radiat Oncol Biol Phys 2007;2007:in press.

29. Kouvaris JR, Kouloulias VE, Vlahos LJ. Amifostine: the first selective-target and broad spectrum radioprotector. Oncologist 2007;12(6):738-47.

30. Ning S, Shuii C, Khan WB, al. e. Effects of keratinocyte growth factor on the proliferation and radiation survival of human squamous cell carcinoma cell lines in vitro and in vivo. Int $J$ Radiat Oncol Biol Phys 1997;40:177-87.

31. Greenberger JS, Epperly MW. Review: antioxidant gene therapeutic approaches to normal tissue radioprotection and tumor radiosensitization. In Vivo 2007;21:141-6.

32. Mittal BB, Pauloski BR, Haraf DJ, et al. Swallowing dysfunction - preventative and rehabilitation strategies in patients with head and neck cancers treated with surgery, radiotherapy and chemotherapy: a critical review. Int J Radiat Oncol Biol Phys 2003;57(5):1219-30.

33. Rosenthal DI, Lewin JS, Eisbruch A. Prevention and treatment of dysphagia and aspiration after chemoradiation for head and neck cancer. J Clin Oncol 2006;24(17):2636-43.

34. Ang KK, Pajak T, Rosenthal D, et al. A phase III trial to compare standard versus accelerated fractionation in combination with concurrent cisplatin for head and neck carcinomas (RTOG 0129): Report of compliance and toxicity. Proc. Am. Soc. Ther Rad Onc (ASTRO), 2007 Annual Meeting, Los Angeles, IJRBOP suppl.

35. List MA, Stracks J, Colangelo L, et al. How do head and neck cancer patients prioritize treatment outcomes before initiating treatment? J Clin Oncol 2000;18(4):877-84.

\section{BODINEJOURNAL}

